
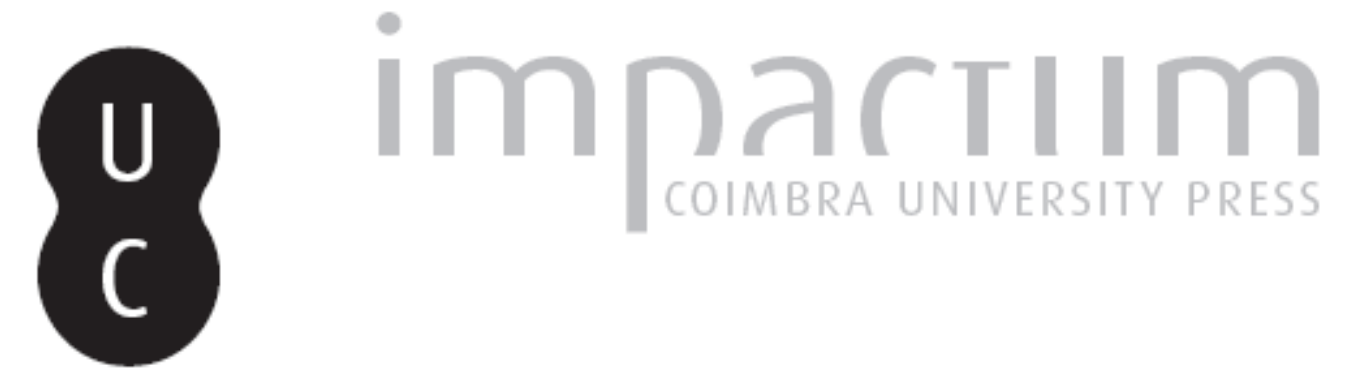

\title{
Um estudo sobre as lucernas encontradas nas escavações de 1966/67 do Teatro Romano de Lisboa
}

\author{
Autor(es): $\quad$ Diogo, A. M. Dias; Sepúlveda, Eurico de \\ Publicado por: Imprensa da Universidade de Coimbra \\ URL \\ persistente: \\ URI:http://hdl.handle.net/10316.2/45363 \\ DOI: \\ DOI:https://dx.doi.org/10.14195/1647-8657_40_7
}

Accessed : $\quad$ 26-Apr-2023 10:05:02

A navegação consulta e descarregamento dos títulos inseridos nas Bibliotecas Digitais UC Digitalis, UC Pombalina e UC Impactum, pressupõem a aceitação plena e sem reservas dos Termos e Condições de Uso destas Bibliotecas Digitais, disponíveis em https://digitalis.uc.pt/pt-pt/termos.

Conforme exposto nos referidos Termos e Condições de Uso, o descarregamento de títulos de acesso restrito requer uma licença válida de autorização devendo o utilizador aceder ao(s) documento(s) a partir de um endereço de IP da instituição detentora da supramencionada licença.

Ao utilizador é apenas permitido o descarregamento para uso pessoal, pelo que o emprego do(s) título(s) descarregado(s) para outro fim, designadamente comercial, carece de autorização do respetivo autor ou editor da obra.

Na medida em que todas as obras da UC Digitalis se encontram protegidas pelo Código do Direito de Autor e Direitos Conexos e demais legislação aplicável, toda a cópia, parcial ou total, deste documento, nos casos em que é legalmente admitida, deverá conter ou fazer-se acompanhar por este aviso.

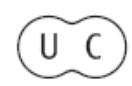


UNIVERSIDADE DE COIMBRA

FACULDADE DE LETRAS

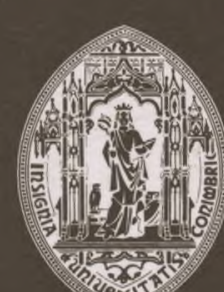

CONIMBRIGA

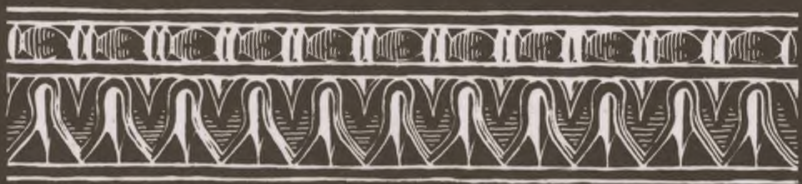

VOLUME XL - 2001 


\section{A. M. DiAs Diogo}

Arqueólogo

\section{EURICo de SePÚlvedA}

Economista

UM ESTUDO SOBRE AS LUCERNAS ENCONTRADAS

NAS ESCAVAÇÕES DE 1966/67 DO TEATRO ROMANO DE LISBOA

"Conimbriga" XL (2001) p. 227-237

Resumo: Publicam-se as lucernas encontradas nas escavações de 1966/67 do teatro romano de Lisboa, existentes nas instalações do Gabinete Técnico do Teatro Romano de Lisboa.

ABSTRACT: In this paper the Authors publish the Roman Lamps found during the excavations of $1966 / 67$ of the Roman Theatre of Lisbon, in the collections of the Gabinete Técnico do Teatro Romano de Lisboa. 
(Página deixada propositadamente em branco) 


\section{UM ESTUDO SOBRE AS LUCERNAS ENCONTRADAS NAS ESCAVAÇÕES DE 1966/67 DO TEATRO ROMANO DE LISBOA}

Publicamos aqui um estudo sobre as lucernas encontradas durante as escavações de 1966/67, efectuadas no teatro romano de Lisboa pela Dra. Irisalva Moita e existentes nas instalações do Gabinete Técnico do Teatro Romano de Lisboa. Segundo esta investigadora, a maioria dos fragmentos de lucernas então recolhidas foram recuperadas nos entulhos das imediações do pulpitum (MOITA, 1970, p. 16).

Este conjunto é constituído por cento e sessenta e quatro fragmentos.

Para o presente estudo seleccionámos cento e quarenta e quatro fragmentos, pertencentes a exemplares distintos, que nos podem oferecer informações quanto ao tipo e à decoração e nos permitem a elaboração de percentagens sobre as origens de fabrico e a cronologia. Trata-se, de facto, de uma publicação preliminar sobre as lucernas encontradas no teatro romano de Lisboa, estando as suas conclusões condicionadas ao estudo das provenientes das escavações que temos vindo a efectuar, desde 1989, neste monumento arqueológico, estas recuperadas em contextos bem definidos.

No que diz respeito aos tipos, a maioria dos fragmentos classificáveis (56,3\%) pertence ao Dressel/Lamboglia 20 e são datáveis da segunda metade do século I até meados do século II (n. os 1 a 6 do nosso Catálogo). Esta quantidade explica-se pelo facto de termos incorporado fragmentos que pelas suas características - orla larga, plana ou abaulada, decorada ou não - parecem coadunar-se com este tipo. Após o tipo $\mathrm{D} / \mathrm{L} 20$ surgem-nos os fragmentos a que não pudemos atribuir qualquer tipología $(20,2 \%)$. Sete exemplares integram-se nos tipos 27 ou 28 de Dressel/Lamboglia, datáveis de todo o século II até ao 
primeiro quartel do terceiro (n. ${ }^{\circ} 7$ a 10). Dos tipos Dressel/ Lamboglia 9 ou 11, lucernas de volutas com uma cronologia de toda a segunda metade do século I, classificámos seis fragmentos, $6,4 \quad \% \quad$ (n. os 11 a 13 do Catálogo). Com três exemplares cada, temos lucernas pertencentes a produções dos séculos III e IV - Dressel/ Lamboglia 30 B (n. ${ }^{\text {s }} 14$ e 15) e Dressel/ Lamboglia 31 (n. ${ }^{\text {os } 16}$ e 17), sendo estas últimas vulgarmente denominadas "paleo-cristãs", de produção tunisina. Com apenas um exemplar, registámos três tipos: Dressel/ Lamboglia $5 \mathrm{C}$, "Fimalampe" ou "Lucerna de canal", de época alto-imperial (n. $\left.{ }^{\circ} 18\right)$; uma lucerna de dois bicos (n. ${ }^{\circ}$ 19) na tradição da "Lucerna de volutas" (LoEschCKe, 1919, Tafel I, III) e classificadas por Bailey como pertencentes ao seu grupo D (BAILEY, 1989, Q 1026 a 1032), que sugere também a possibilidade de existência de produções mais tardias, abrangendo todo o século II e, por fim ( $\left.\mathrm{n}^{\circ} 20\right)$, o bico de uma lucerna de tipo "Rio Tinto/ Aljustrel" (ALARCÃo e AlARCÃO, 1966, p. 19, 51,52 e 78).

\section{Quadro dos fragmentos com forma:}

\begin{tabular}{|l|r|r|}
\hline TIPO & $\#$ & \multicolumn{1}{|c|}{} \\
\hline D/L 5C & 1 & 1,1 \\
\hline D/L 9 ou 11 & 6 & 6,4 \\
\hline D/L 20 & 53 & 56,3 \\
\hline D/L 27 ou 28 & 7 & 7,4 \\
\hline D/L 30B & 3 & 3,2 \\
\hline D/L 31 & 3 & 3,2 \\
\hline Bailey D & 1 & 1,1 \\
\hline Rio Tinto/Aljustrel & 1 & 1,1 \\
\hline Indeterminadas & 19 & 20,2 \\
\hline Total & $\mathbf{9 4}$ & $\mathbf{1 0 0}$ \\
\hline
\end{tabular}

No que diz respeito às asas, foi-nos possível encontrar fragmentos pertencentes a quatro dos tipos de Ponsich (Ponsich, 1961, p. 42 e 43, Fig. 9): o 4, datável de meados do século I, com apenas um exemplar (n. $\left.{ }^{\circ} 21\right) ;$ o 7, com 11 exemplares (22,9\%) e datável dos séculos I e II (n.os 22 e 23); o 8, com 7 exemplares (14,5\%), datável dos séculos II e 
III (n.os 24 a 28) o 9, com apenas um exemplar (n. ${ }^{\circ}$ 29), datável dos séculos IV e V. A maioria dos fragmentos $(28=58,2 \%)$ apresentam características pertencentes aos tipos Ponsich 7 e 8, podendo ter uma cronologia compreendida entre os séculos II e III (n. os 30 a 34).

\section{Quadro dos fragmentos de asas:}

\begin{tabular}{|l|r|r|}
\hline TIPO & $\#$ & $\%$ \\
\hline Ponsich 4 & 1 & 2,2 \\
\hline Ponsich 7 & 11 & 22,9 \\
\hline Ponsich 7/8 & 28 & 58,2 \\
\hline Ponsich 8 & 7 & 14,5 \\
\hline Ponsich 9 & 1 & 2,2 \\
\hline Total & $\mathbf{4 8}$ & $\mathbf{1 0 0}$ \\
\hline
\end{tabular}

No que respeita às produções, dividem-se em dois grupos: produção local, que aqui é dominante, com 104 exemplares (63,5\%) e importados, com 60 exemplares $(36,5 \%)$, tendo nós aqui encontrado fabricos hispânicos, itálicos e norte-africanos.

Apenas cinco exemplares conservam vestígios decorativos no disco. Destes, três são demasiado pequenos ou deteriorados para permitir uma interpretação (n. ${ }^{o s} 12,35$ e 36). Dos restantes, o primeiro (n. ${ }^{\circ}$ 11) parece ser um cavalo, com paralelo em Conimbriga (AlARCÃo e PONTE, 1976, n. $\left.{ }^{\circ} 49\right)$ e o segundo parece apresentar parte de dois raios de Sol (n. $\left.{ }^{\circ} 37\right)$.

Várias orlas encontram-se decoradas, estando representados os seguintes motivos:

1 - Círculos (n.os 38 e 39), decoração rara. Apenas encontramos paralelos no Museu Britânico (BAILEY, 1980, Plate 84, Q 1405), Cartago (Deneauve, 1974, Planche LXXVIII, n. ${ }^{\circ}$ 850) e Ceuta (FERnánDEZ Sotelo, 1994, p. 40 e 42). Para Portugal, os paralelos registados encontram-se em Alcácer do Sal (CABRAL, 1974/ 1977, Est. II, n. ${ }^{\circ}$ 6) e Conimbriga (AlARCÃo e PONTE, 1976, n. ${ }^{\circ}$ 26), onde foi também encontrado um molde (BELCHIOR, 1969, Est. A). 
2 - Estrias radiais (n. ${ }^{\mathbf{8}} 40$ e 41). Incisões direitas ou ligeiramente onduladas, é um motivo muito utilizado em lucernas do tipo D/L 20, pelo que são muito abundantes os paralelos.

3 - Folha de videira (n. $\left.{ }^{\circ} 10\right)$, decoração constituída por parra alternando com cachos de uvas. Esta decoração é muito vulgar no norte de África. Em Portugal era já conhecido em Conimbriga (AlARCÃo e Ponte, 1976, n. ${ }^{\circ}$ 62), Santa Bárbara (MAIA e MAIA, 1997, lu 1).

4 - Grinaldas de folha de oliveira (n. ${ }^{\circ}$, 8 e 9), decoração utilizada em lucernas dos finais dos Antoninos a meados do século III, esta decoração também é conhecida como ramos de trifoliáceas alternando com frutos. Em Portugal conhecemos dois exemplares: um do Museu Nacional de Arqueologia, sem proveniência (ALMEIDA, 1952, n. ${ }^{\circ}$ 103) e de Tróia (CostA, 1973, Est. LII).

5 - Ovas (n. ${ }^{\circ} 32$ e 43). Trata-se de uma decoração muito comum em lucernas de tipo D/L 20.

6 - Pérolas (n. ${ }^{\text {ss }} 14$ e 15). Decoração muito comum, utilizada em lucernas tardias dos finais do século III e todo o século IV.

Por último, o nosso fragmento $\mathrm{n}^{\circ} 13$ apresenta uma decoração, aparentemente anelar, entre a orla e o disco, para o qual apenas encontrámos um paralelo em Portugal (Conimbriga, BELCHIOR, 1969, p. 36, Est. V.1)

Registámos a existência de três marcas de oleiro, todas incompletas. A $n^{\circ} 44$ não nos permite qualquer solução de leitura, pois dela apenas resta uma letra que poderá ser um $\mathrm{E}$ ou um $\mathrm{F}$. A n. ${ }^{\circ} 45$, em que se lê $\mathrm{CI}[\ldots]$ poderá ter como paralelo a marca de Tróia CIO, que é atribuída a um oleiro hispânico (CosTA, 1973, pág. 73 e 74) ou a $\mathrm{Cl}$ de proveniência desconhecida, que se encontra no Museu de Nápoles (PAvolini, 1977, Tabela II - índice dei bolli). A última marca, de que apenas se conserva um círculo (n. ${ }^{\circ}$ 46), tem abundantes paralelos e poderá pertencer a marcas de diferentes oleiros.

\section{CATÁlOGO}

1 - Fragmento de disco, bico e parede do depósito. Tipo Dr./Lam. 20. Pasta vermelho-rosada, dura e muito fina. Superfícies bege-rosadas, com manchas acinzentadas.

2 - Fragmento de disco, orla e bico. Tipo Dr./Lam. 20. Pasta rosa-alaranjada, de textura folheada e muito fina.

Conimbriga, 40 (2001) 225-235 
3 - Fragmento de disco, orla e parede de depósito, com bico. Tipo Dr./Lam. 20. Pasta amarelada, muito fina, com minúsculas partículas negras.

4 - Fragmento de disco, orla e bico. Tipo Dr./Lam. 20. Pasta bege-alaranjada. Muito dura e fina, com minúsculas calcites muito abundantes.

5 - Fragmento de disco e orla. Tipo Dr./Lam. 20. Conserva o orifício de arejamento e vestígios do de alimentação. Pasta bege-alaranjada, muito dura e fina, com partículas negras e minúsculas calcites.

6 - Fragmento de disco, orla, parede do depósito e bico. Tipo Dr./Lam. 20. Pasta laranja-acastanhada, muito dura e fina, com minúsculas calcites. Engobe acinzentado, espesso.

7 - Fragmento de orla e parede de depósito, com asa. Tipo Dr./ /Lam. 27 ou 28. Orla decorada. Pasta alaranjada, muito dura e fina, com minúsculos nodulos ocres. Superficie externa revestida com engobe vermelho-acastanhado, manchado.

8 - Fragmento de disco e orla. Tipo Dr./Lam. 27 ou 28. Orla decorada. Pasta bege, muito fina e dura, com minúsculas calcites. Superficie externa com engobe castanho-acinzentado, irregular.

9 - Fragmento de parede de depósito e orla. Tipo Dr./Lam. 27 ou 28. Orla decorada. Pasta amarelada, muito fina, com minúsculas partículas negras.

10 - Fragmento de depósito, orla, disco e bico. Tipo Dr./Lam. 27 ou 28. Orla e disco decorados. Pasta bege, muito fina e dura, com minúsculas calcites. Superficie externa revestida com engobe castanho-acinzentado, irregular.

11 - Fragmento de disco e orla. Tipo Dr./Lam. 9 ou 11. Disco decorado e conservando o orifício de arejamento. Pasta bege, muito fina e dura, com pequenos alvéolos e minúsculas partículas negras. Superficie externa revestida com engobe castanho acinzentado, irregular.

12 - Fragmento de disco e orla. Tipo Dr./Lam. 9 ou 11. Disco e orla, decorados. Conserva vestígios do orifício de alimentação. Pasta alaranjada, muito fina, branda e de textura folheada.

13 - Fragmento de disco, orla e arranque de asa. Tipo Dr./Lam. 9 ou 11. Disco moldurado. Pasta creme-amarelada, branda, muito fina, com minúsculos alvéolos.

14 - Fragmento de disco e orla. Tipo Dr./Lam. 30 B. Orla decorada. O disco conserva vestígios do orifício de alimentação. Pasta ala- 
ranjada, de textura folheada, com minúsculos quartzos, calcites e partículas de mica.

15 - Fragmento de parede de depósito, orla e asa. Tipo Dr./Lam.

30 B. Orla decorada. Pasta alaranjada, muito fina, branda, com minúsculas partículas negras. Superfície externa revestida com engobe vermelho-acastanhado, degradado.

16 - Fragmento de disco e orla.. Tipo Dr./Lam. 31 . Decorado com duas incisões junto ao arranque do bico. Pasta avermelhada muito fina e dura.

17 - Fragmento de parede de depósito, disco e orla. Tipo Dr./Lam.

31 . Orla moldurada. Pasta vermelho-alaranjada muito fina e dura, com minúsculas partículas negras.

18 - Fragmento de disco, orla e bico. Tipo Dr./Lam. 5 C. ou Firmalampe". Conserva o canal e vestígios do orifí́cio de alimentação. Pasta laranja-avermelhada muito fina e dura, com abundantes alvéolos. Superfície externa bege.

19 - Fragmento de disco, orla e um dos bicos. Tipo Bailey D. Pasta vermelho-alaranjada fina e muito dura.

20 - Fragmento de bico. Tipo Rio Tinto/Aljustrel. Pasta creme, branda e muito fina.

21 - Fragmento de asa. Tipo Ponsich 4. Pasta creme, fina e dura, com minúsculas partículas negras.

22 - Fragmento de parede de depósito e arranque de asa. Tipo Ponsich 7. Asa decorada com duas ranhuras longitudinais no arranque. Pasta bege, muito fina e dura, com abundantes pequenos alvéolos. Superfície externa com engobe castanho-acinzentado, manchado.

23 - Fragmento de parede de depósito, com asa. Tipo Ponsich 7. Asa decorada no dorso com duas ranhuras longitudinais. Pasta laranja-acastanhada, muito fina e dura, com minúsculas calcites e partículas negras. Conserva vestígios de engobe avermelhado, espesso.

24 - Fragmento de parede de depósito, disco e orla com asa. Tipo Ponsich 8. Asa decorada com duas ranhuras longitudinais no dorso. Pasta bege-alaranjada muito dura e fina com minúsculos alvéolos e calcites. Engobe vermelho-acastanhado, manchado.

25 - Fragmento de parede de depósito, com asa tipo Ponsich 8. Pasta laranja-rosada, de textura folheada branda e fina, com minúsculos quartzos e micas.

26 - Fragmento de parede de depósito e orla com asa. Tipo Ponsich 8. Pasta rosada de textura folheada dura e fina.

Conimbriga, 40 (2001) 225-235 
27 - Fragmento de parede de depósito e orla com asa. Tipo Ponsich 8. Asa decorada com duas ranhuras longitudinais no dorso. Pasta bege-rosada muito dura e fina, com partículas negras.

28 - Fragmento de parede de depósito, orla e disco, com asa. Tipo Ponsich 8. Pasta laranja-avermelhada, muito fina e dura. Superfície, externa com vestígios de engobe creme.

29 - Fragmento de base, parede de depósito e arranque da asa. Tipo Ponsich 9. Pasta bege-rosada, de textura folheada, muito fina e dura. Superfície externa alaranjada.

30 - Fragmento de parede de depósito e orla, com asa. Tipo Ponsich 7/8. Pasta rosa-alaranjada, dura e fina, com minúsculas calcites e nódulos ocres.

31 - Fragmento de parede de depósito, orla e disco, com asa. Tipo Ponsich 7/8. Pasta rosa-alaranjada, muito dura e fina.

32 - Fragmento de parede de depósito e orla, com asa. Tipo Ponsich 7/8. Pasta laranja-acastanhada, dura e fina, com minúsculos nódulos ocres.

33 - Fragmento de parede de depósito, com asa. Tipo Ponsich 7/8. Asa decorada com duas ranhuras longitudinais no dorso. Pasta avermelhada e dura, com abundantes minúsculas calcites. Superfície externa conservando vestígios de engobe amarelado.

34 - Fragmento de parede de depósito, com asa. Tipo Ponsich 7/8. Pasta laranja-acastanhada, branda e muito fina.

35 - Fragmento de parede de depósito, orla e disco, com asa. Tipo indeterminado, talvez Dr./Lam. 20. Disco decorado e asa com duas ranhuras longitudinais no topo. Pasta bicolor, amarelada para o exterior e rosada para o interior, dura e muito fina.

36 - Fragmento de parede de depósito, orla e disco, com arranque de asa. Possivelmente tipo Dr./Lam. 20. Disco decorado. Pasta rosada, dura e muito fina.

37 - Fragmento de parede de depósito, orla, disco e base. Possivelmente tipo Dr./Lam. 20. Disco decorado. Pasta bege-alaranjada, dura e muito fina, com minúsculas calcites e partículas negras. Superfície externa revestida com engobe vermelho-acastanhado, manchado.

38 - Fragmento de parede de depósito e orla. Tipo indeterminado. Orla decorada. Pasta bege-alaranjada, dura e fina, com abundantes calcites minúsculas. Conserva vestígios de engobe castanho-acinzentado, manchado.

39 - Fragmento de parede de depósito, orla, disco e arranque da 
asa. Tipo indeterminado. Orla e disco decorados. Pasta bege-rosada, dura e muito fina, com minúsculas calcites. Conserva vestigios de engobe avermelhado na superficie externa.

40 - Fragmento de base, parede de depósito e orla, com asa. Tipo Dr./Lam. 20. Orla decorada, asa com duas ranhuras longitudinais no dorso. Pasta amarelada, branda e fina, com abundantes minúsculas partículas negras. Superfície externa revestida com engobe homogéneo, vermelho-acastanhado, com reflexos dourados.

41 - Fragmento de parede de depósito e orla. Tipo Dr./Lam. 20. Orla decorada. Pasta avermelhada, muito dura, fina, com abundantes minúsculas calcites. Superfícies cinzento-alaranjadas.

42 - Fragmento de parede de depósito e orla. Tipo indeterminado. Orla decorada. Pasta avermelhada, muito dura, fina com abundantes minúsculas calcites. Conserva vestígios de engobe acinzentado.

43 - Fragmento de parede de depósito e orla, com asa. Tipo Dr./Lam. 20. Orla decorada e asa com duas ranhuras longitudinais no dorso. Pasta bege-amarelada, dura e fina, com minúsculos alvéolos. Conserva vestígios de engobe laranja-acastanhado com reflexos dourados.

44 - Fragmento de base e parede de depósito. Tipo indeterminado. A base apresenta parte de uma marca estampada: E[...]? Pasta bege-alaranjada, muito dura e fina, com minúsculas calcites e partículas ocres. Conserva vestígios de engobe acinzentado.

45 - Fragmento de base e parede de depósito. Tipo indeterminado. A base apresenta parte de uma marca esgrafitada: CI[ ...]. Pasta bege-amarelada, muito dura $\mathrm{e}$ fina. Conserva vestígios de engobe laranja-acastanhado.

46 - Fragmento de base e parede de depósito. Tipo indeterminado. A base apresenta um círculo impresso, possivelmente pertencente a uma marca. Pasta bege-amarelada, dura e fina, com minúsculas partículas negras. Conserva vestígios de engobe castanho acinzentado, manchado.

\section{BIBLIOGRAFIA}

Alarcão, A. e Ponte, S. (1976) - "Les Lampes", Fouilles de Conimbriga. VI-Céramiques Diverses et Verres, Paris, Diffusion E. de Boccard.

Conimbriga, 40 (2001) 225-235 
Alarcão, J. (1982) - "O teatro romano de Lisboa", Actas del Simposio 'El Teatro en la Hispania Romana “, Badajoz, p. 287-302.

Alarcão, J. e Alarcão, A. (1966) - "O espolio da necrópole luso-romana de Valdoca (Aljustrel)", Conimbriga, 5, p. 7-104.

BAILEy, D. (1980) - A Catalogue of the Lamps in the British Museum. 2. Roman Lamps made in Italy, Londres, The Trustees of the British Museum.

Bailey, D. (1989) - A Catalogue of the Lamps of the British Museum. Ill Roman Provincial Lamps, Londres, The Trustees of the British Museum.

Belchior, Claudette (1969) - Lucernas Romanas de Conimbriga, Conimbriga, Museu Monográfico de Conimbriga.

Cabral, Maria E. F. (1974/ 1977) - "Lucernas romanas de Alcácer do Sal”, O Arqueólogo Português, Série III, 7/9, p. 347-354.

Costa, Maria E. F. (1973) - Lucernas Romanas de Tróia de Setúbal, Lisboa, Faculdade de Letras de Lisboa (Tese de licenciatura policopiada).

Deneauve, Jean (1974) - Lampes de Carthage, Paris, Éditions du Centre National de la Recherche Scientifique.

Diogo, A. M. Dias (1993) - "O Teatro Romano de Lisboa. Noticia sobre as actuáis escavações", Cuadernos de Arquitectura Romana, 2, Murcia, p. 217-224.

Diogo, A. M. Dias E TRINDADE, LaURA (em publicação) - "Ânforas e sigillatas tardias (claras, foceanas e cipriotas) provenientes das escavações de 1966/67 do teatro romano de Lisboa", Revista Portuguesa de Arqueologia.

Diogo, A. M. Dias e Vital, Nestor fatia (em publicação) - "As moedas das escavações arqueológicas do Teatro Romano de Lisboa (1989 - 1993)", Revista de Arqueologia da Assembleia Distrital de Lisboa, 4.

Duarte, Ana L. C. e Raposo, Jorge M. C. (1996) - "Elementos para a caracterização das produções anfóricas da Quinta do Rouxinol (Corroios/ Seixal)", Ocupação Romana dos Estuários do Teio e do Sado (Nova Enciclopédia, 54), Lisboa, p. 237-247.

Fernández Sotelo, Emilio (1994) - "Un Vertedero del Siglo III en Ceuta", Monografias Transfretana, 1, Ceuta, Instituto de Estudios Ceuties, p. 9-55.

Loeschcke, Siegfried (1919) - Lampen aus Vindonissa. Ein Beitrag zur Geschichte von Vindonissa und des antiken Beleuchtungswesens, Zurique.

maia, Maria e Maia, Manuel (1997) - Lucernas de Santa Bárbara, Castro Verde, Ed. Cortiçol.

Moita, IRISAlva (1970) - “O Teatro Romano de Lisboa”, Revista Municipal, 124/125, p. 7-37.

Pavolini, Carlo (1977) - "Le lucerne fittili romane del Museo Nazionale di Napoli", L'instrumentum domesticum di Ercolano e Pompei nella prima etá imperiale (Cuaderni di Cultura Materiale, 1), Roma, p. 33-51.

Silva, C. T. da e Coelho-So aRes, A. (1980-81) - "A Praça do Bocage (Setúbal) na época romana. Escavações arqueológicas de 1980”, Setúbal Arqueológica, 6-7, p. 249-284.

ViAnA, Abel (1948) - "Notas históricas, arqueológicas e etnográficas do Baixo Alentejo", Arquivo de Beja, 5, fases. 1 e 2, p. 3-62. 

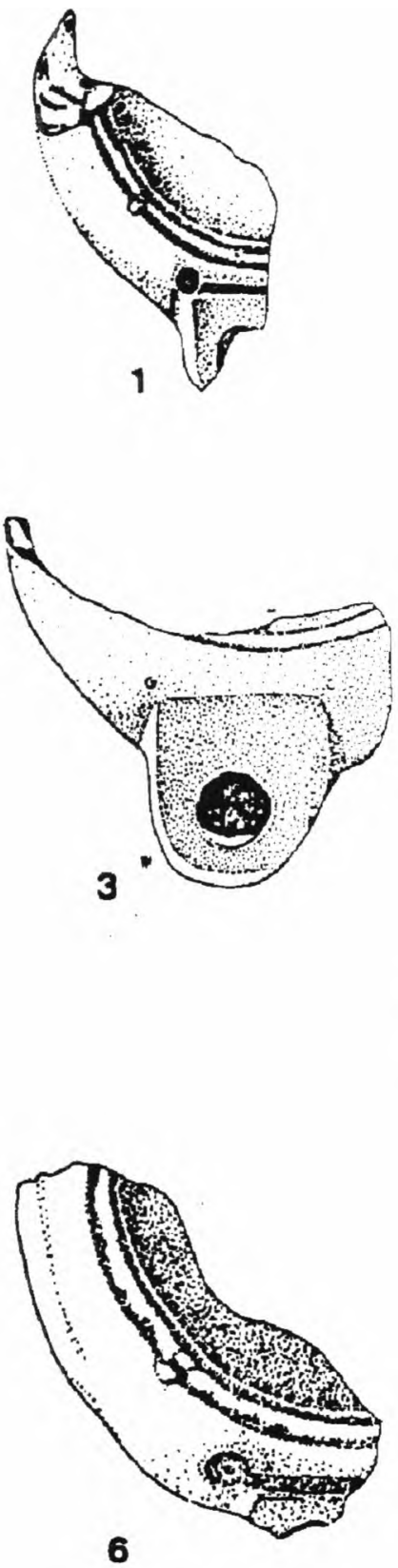
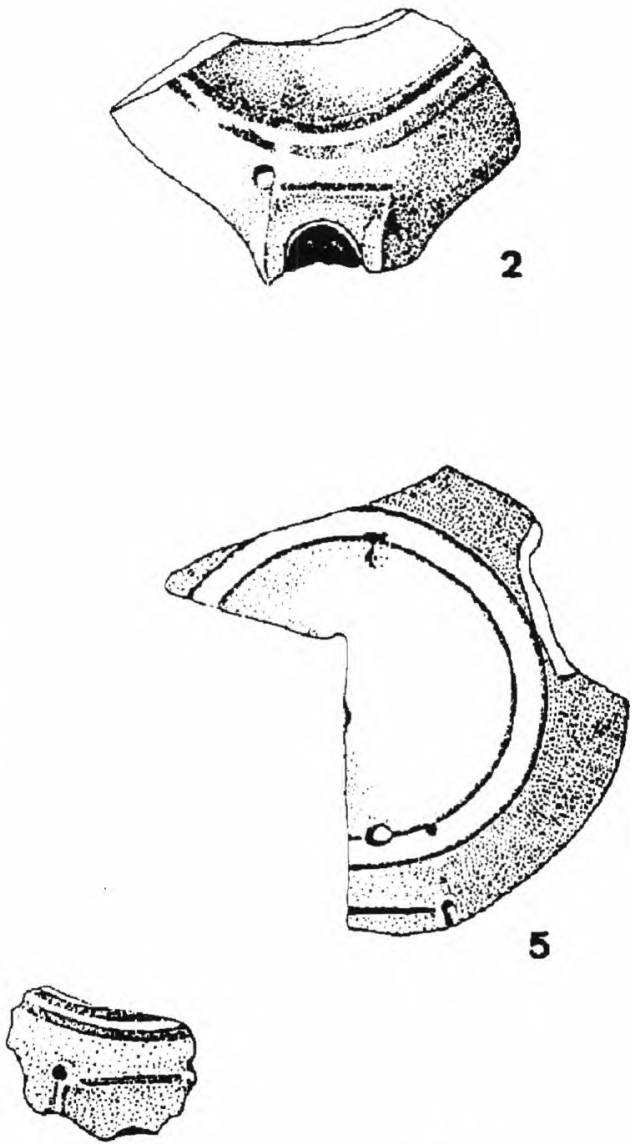

4
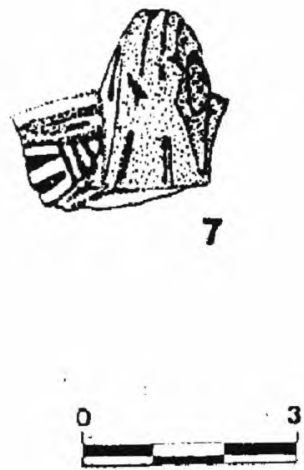

Lucernas do teatro romano de Lisboa. 


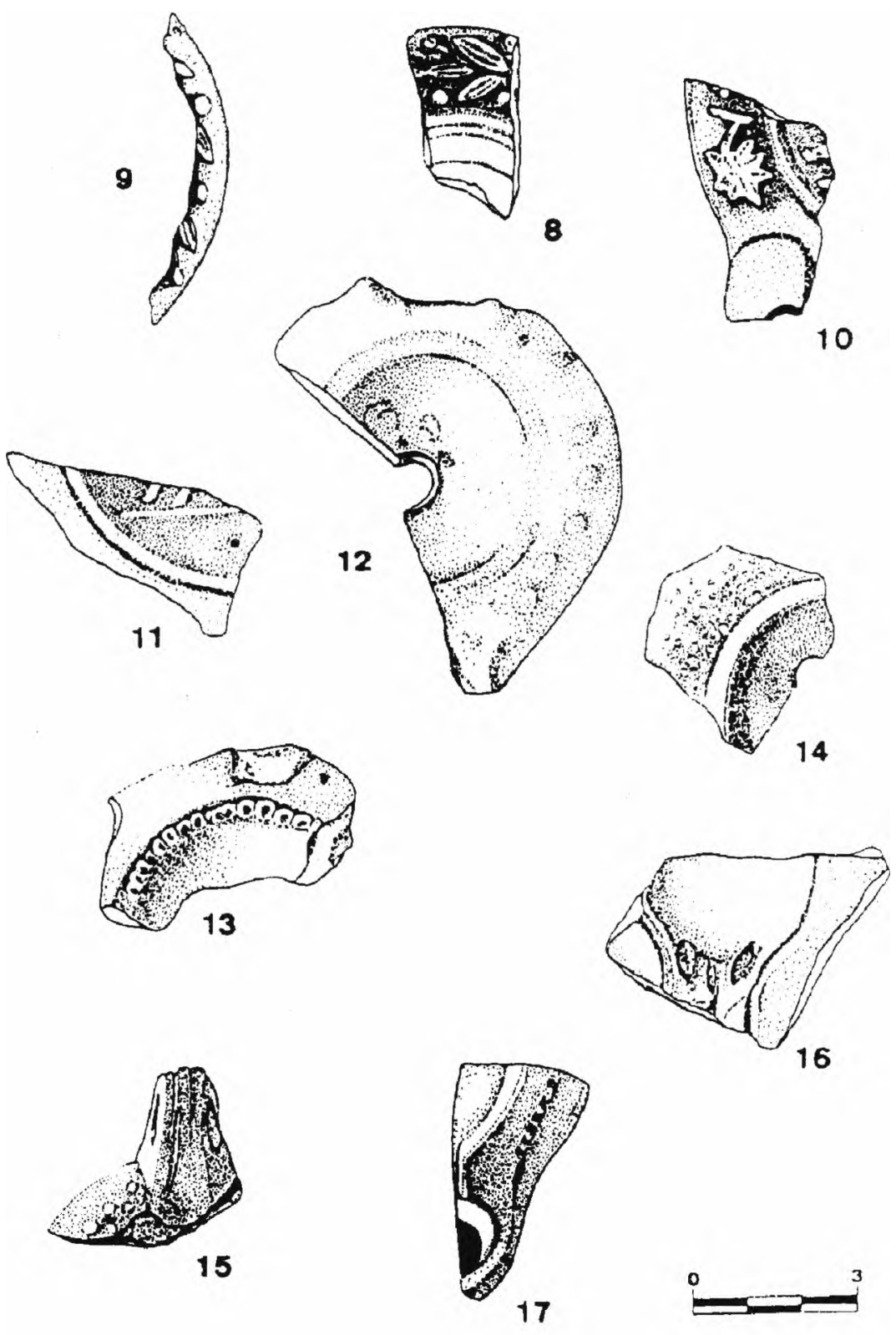

Lucernas do teatro romano de Lisboa. 


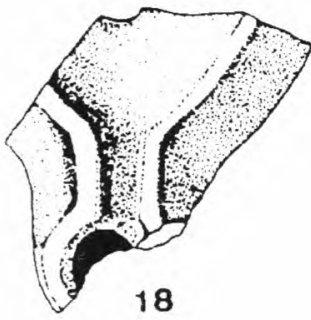

18
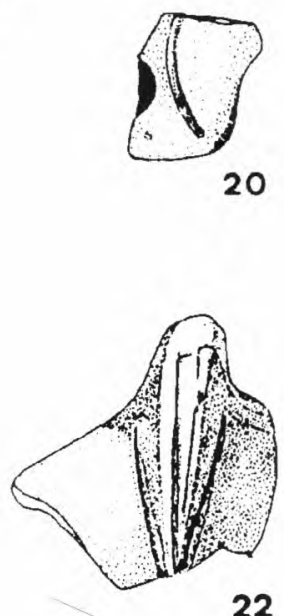

22
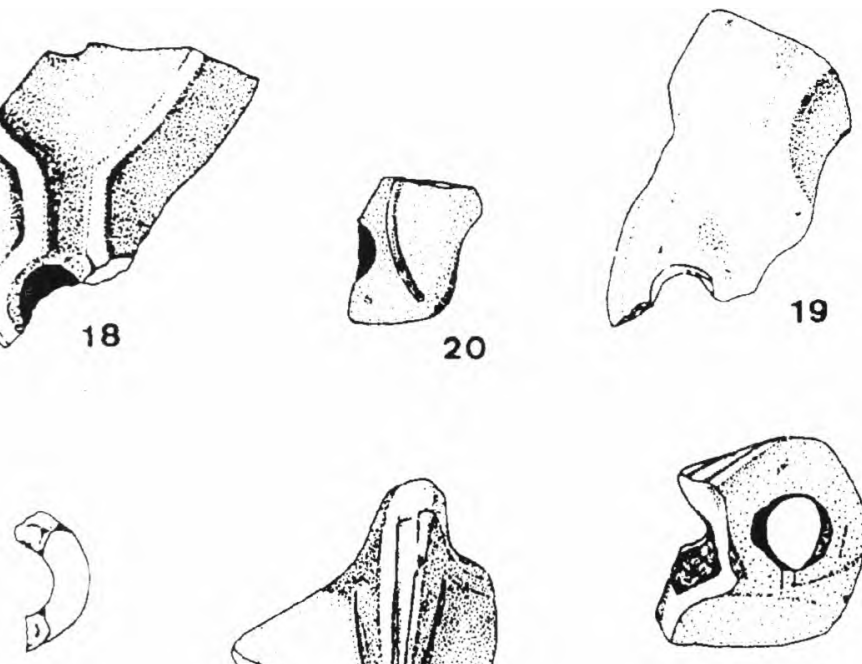

21

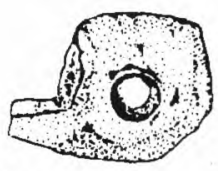

25

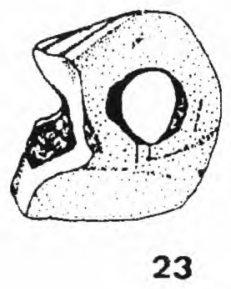

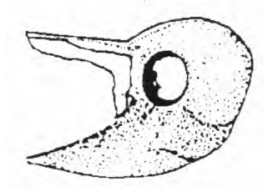

24
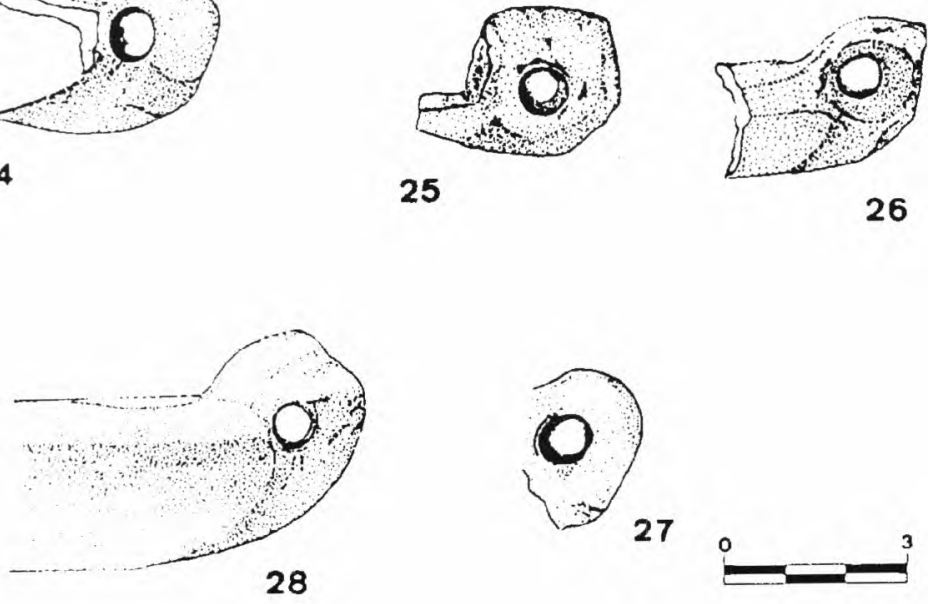

27

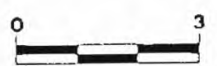

Lucernas do teatro romano de Lisboa. 


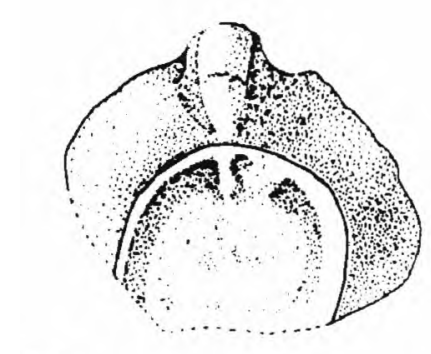

29
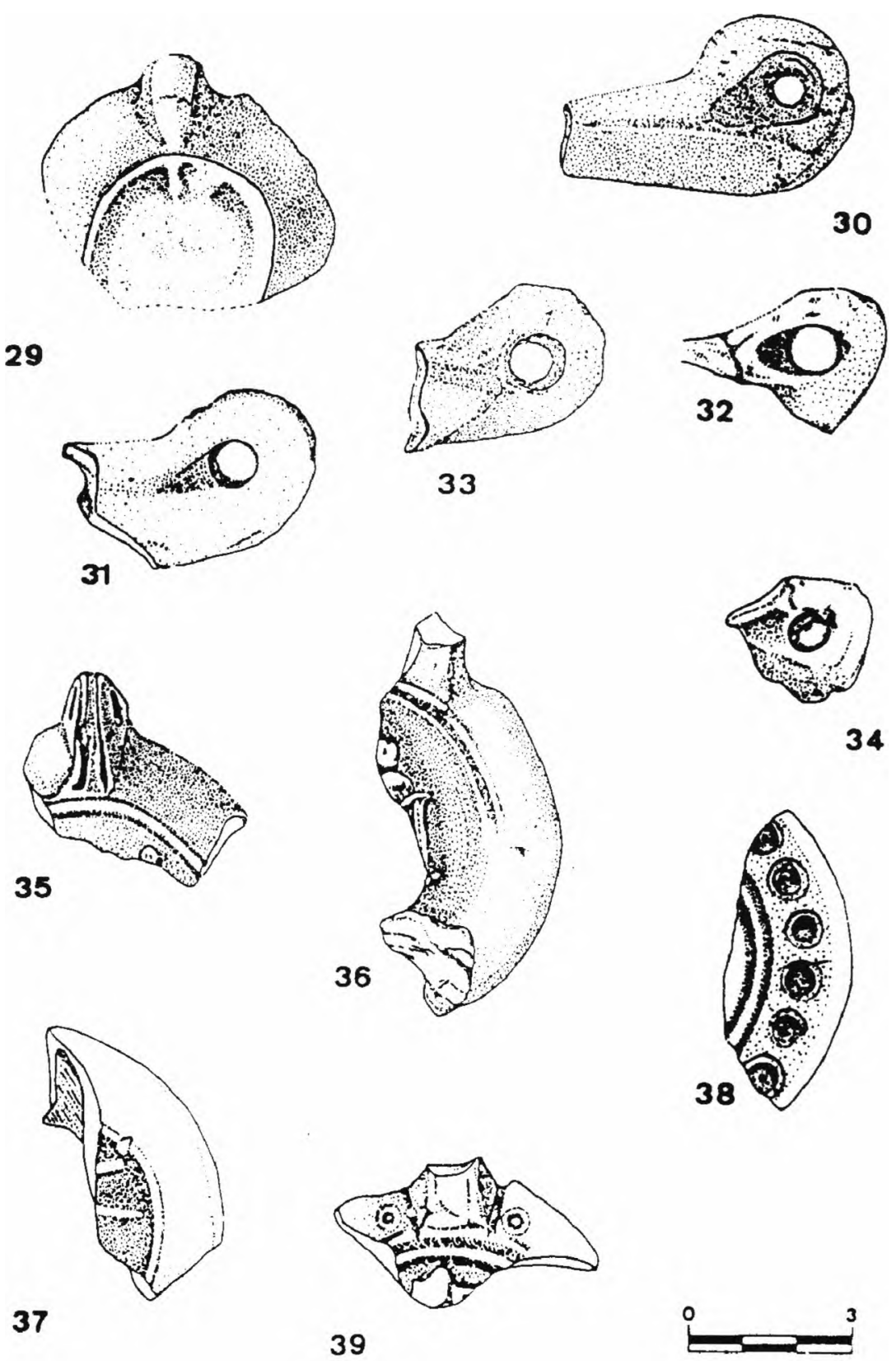

37

Lucernas do teatro romano de Lisboa. 

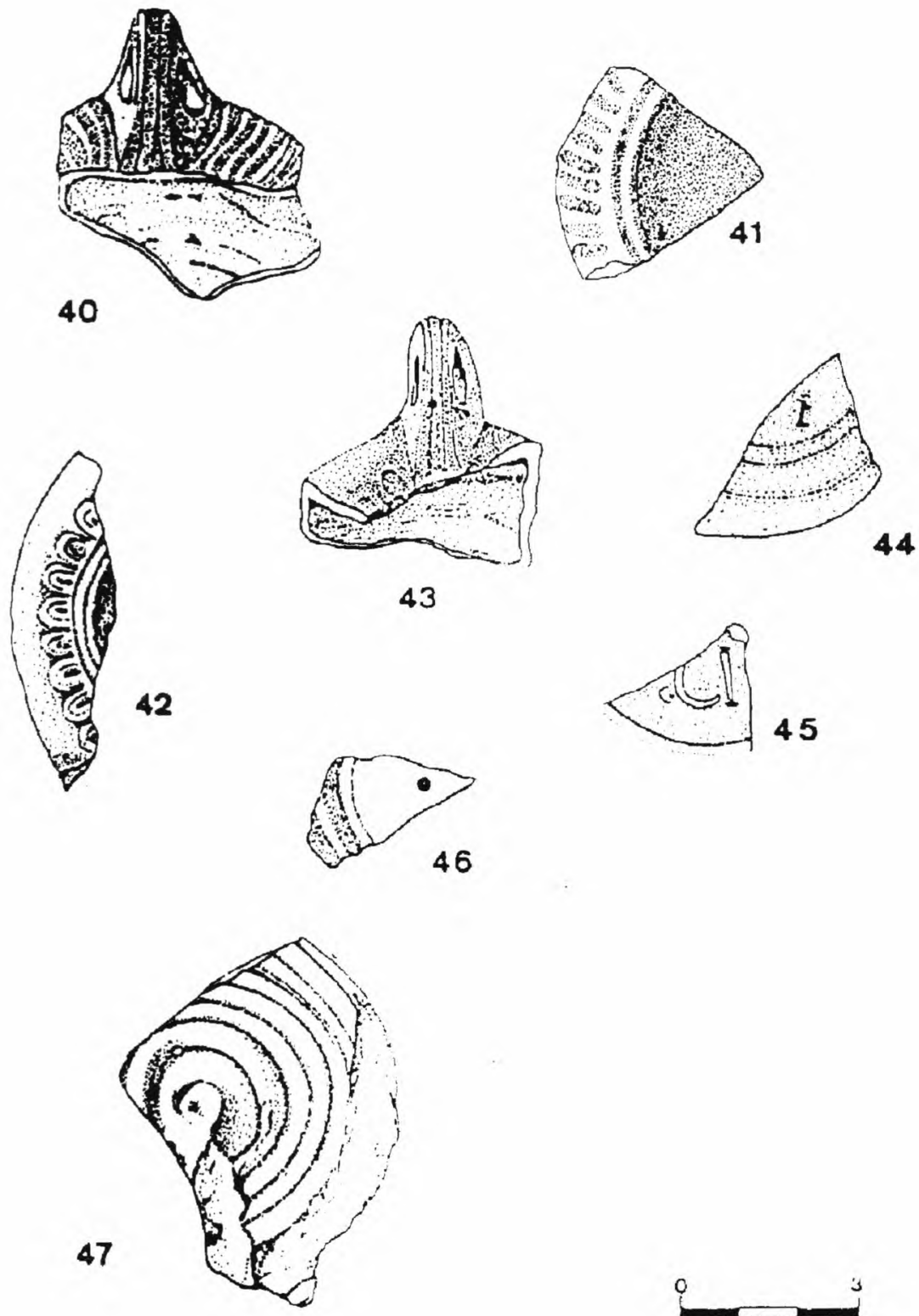

Lucernas do teatro romano de Lisboa. 